\title{
Human Vital Sign Examination Device (Parameter Laju Pernafasan dan Tekanan Darah)
}

\author{
Aulia Handayani Putra*1, Tri Harjono ${ }^{2}$ \\ ${ }^{1}$ Universitas Muhammadiyah Yogyakarta, Indonesia \\ ${ }^{2}$ Rumah Sakit Umum Bethesda, Indonesia
}

\section{INFO ARTIKEL}

Alamat Web Artikel:

https://journal.umy.ac.id/index.php /mt/article/view/7333

DOI:

https://doi.org/10.18196/mt.020112

Data Artikel:

Diterima:

11 Maret 2020

Direview:

22 April 2020

Direvisi :

30 April 2020

Disetujui :

15 Mei 2020

Korespondensi:

auliahandayaniputra@gmail.com

\begin{abstract}
ABSTRAK
Dalam menyikapi pentingnya kesadaran pada penyakit hipertensi dan paru-paru, maka penting pula bagi kita untuk memiliki alat pengukur tekanan darah dan laju pernafasan. Hal ini dilakukan guna memantau kesehatan. Pada masyarakat awam, penggunaan tensimeter dan alat ukur laju pernafasan secara baik dan benar sangat sulit untuk dilakukan, karena dibutuhkan pengetahuan yang cukup agar dapat menggunakan dan membaca hasil dari pengukuran. Dengan bantuan alat human vital sign examination device dengan parameter laju pernafasan dan tekanan darah, maka alat yang sederhana ini dapat mengurangi tingkat kematian pada masyarakat pada negara berkembang. Alat ini berfungsi untuk mempermudah pengguna dalam memantau tekanan darah dan laju pernapasan. Alat ini menggunakan sensor MPX5050GP yang berfungsi untuk menyadap sinyal tekanan darah dengan metode oscillometric dan sensor miccodensor FC04 yang berfungsi untuk menyadap sinyal laju pernafasan. Berdasarkan hasil pengujian modul pada parameter tekanan darah dengan 5 responden, maka didapatkan persentase error dan kesalahan absolut terendah sebesar $4,2 \mathrm{mmHg}$ dengan persentase 3,64\% pada tekanan sistole dan 2,4 $\mathrm{mmHg}$ dengan persentase $3,8 \%$ pada tekanan diastole, dan kesalahan absolut tekanan darah yang paling besar yaitu $8,8 \mathrm{mmHg}$ dengan persentase $6,16 \%$ pada tekanan sistole dan 7,8 $\mathrm{mmHg}$ dengan persentase $8,8 \%$ pada tekanan diastole, sedangkan pada laju pernafasan nilai kesalahan absolut tertinggi yaitu 1,6 brpm dengan persentase error $9,7 \%$ dan nilai terendah yaitu 0,8 brpm dengan persentase error $4,1 \%$.
\end{abstract}

Kata Kunci: Laju Pernafasan, Miccodenser FC-04, MPX5050GP, Oscillometric, Tekanan

\begin{abstract}
In addressing the importance of awareness of hypertension and lung disease, having a blood pressure measuring device and respiratory rate is necessary to monitor health. For ordinary people, the use of tensimeters and measuring instruments for breathing rate properly and correctly is very difficult because it requires sufficient knowledge to use and read the measurements' results. With the help of a human vital sign examination device with respiratory rate parameters and blood pressure, this simple tool is expected to reduce the death rate for people in developing countries. The tool eases the users to monitor blood pressure and respiratory rate by using the MPX5050GP sensor to tap blood pressure signals with the oscillometric method and the FC-04 miccodenser sensor to tap the respiratory rate signal. Based on module testing results on blood pressure parameters with five respondents, the lowest error and absolute error percentage was $4.2 \mathrm{mmHg}$ with a percentage of $3.64 \%$ at systolic pressure and $2.4 \mathrm{mmHg}$ with a percentage of $3.8 \%$ at diastolic pressure. Also, the greatest absolute error of blood pressure was $8.8 \mathrm{mmHg}$ with a percentage of $6.16 \%$ at systolic pressure and $7.8 \mathrm{mmHg}$ with a percentage of $8.8 \%$ at diastolic pressure, while at the respiratory rate, the highest absolute error value was 1.6 brpm with the percentage error is $9.7 \%$ and the lowest value is 0.8 brpm with an error percentage of $4.1 \%$.
\end{abstract}

Keywords: Respiratory Rate, Miccodenser FC-04, MPX5050GP, Oscillometric, Pressure 


\section{Putra, Harjono}

Human Vital Sign Examination Device

\section{PENDAHULUAN}

Penyakit hipertensi biasanya tidak menampakkan gejala dan menyerang seseorang tanpa disadari. Biasanya, seseorang mengetahui dirinya mengalami hipertensi setelah memeriksakan tekanan darahnya. Penderita hipertensi datang ke dokter, umumnya dalam keadaan sudah parah karena tidak tahu bahwa dirinya mengidap penyakit hipertensi. Seseorang akan memperhatikan resiko bahaya hipertensi ketika ada keluarga dekatnya, yaitu ayah, ibu, kakak, atau adiknya yang meninggal dunia terkena serangan jantung ataupun lumpuh dikarenakan stroke sebagai komplikasi hipertensi. Hal ini penting untuk memeriksakan tekanan darah secara berkala untuk mendeteksi secara dini terjadinya peningkatan tekanan darah [1].

Laju pernafasan adalah cepat atau lambatnya saat bernafas. Alat ukur laju pernafasan (respiration rate) adalah suatu alat yang digunakan untuk memantau laju pernafasan dalam jangka waktu 1 menit, pengukuran ini biasa digunakan untuk mendiagnosa suatu penyakit. Menurut data WHO, pengukuran normal pada orang dewasa adalah 12 hingga 20 brpm [2]. Dari hasil pengukuran frekuensi pernafasan biasa disebut eupnea, sedangkan jumlah pernafasan yang melebihi rata-rata disebut tachyonea dan jumlah pernafasan yang lebih rendah dari rata-rata jumlah pernafasan biasa disebut bradypena. Karena itu akurasi jumlah frekuensi pernapasan perlu diperhatikan mengingat pentingnya dalam mendiagnosa suatu penyakit.

Dalam menyikapi pentingnya kesadaran pada penyakit hipertensi dan paru-paru, maka penting pula bagi kita untuk memiliki alat pengukur tekanan darah dan laju pernafasan, guna memantau kesehatan pada diri kita. Pada masyarakat awam, penggunaan tensimeter dan alat ukur laju pernafasan secara baik dan benar sangat sulit untuk dilakukan, karena dibutuhkan pengetahuan yang cukup agar dapat menggunakan dan membaca hasil dari pengukuran. Pada era modern seperti saat ini, telah dikenal adanya patient monitor atau bedside monitor. Patient monitor ini lebih praktis dibandingkan dengan tensimeter dan alat ukur laju pernafasan, karena didalam alat ini terdapat beberapa parameter, yaitu ECG, respirasi, suhu, tekanan darah, dan $\mathrm{SpO}_{2}$. Parameter adalah bagianbagian fisiologis dari pasien yang diperiksa melalui pasien monitor. Jika diketahui ada sebuah pemantau pasien dengan 5 parameter, maka yang dimaksud dari lima parameter tersebut adalah banyak jenis pemeriksaan yang bisa dilakukan oleh patient monitor tersebut.

Uraian permasalahan tersebut menjadi latar belakang untuk merancang suatu alat yang dapat digunakan pada masyarakat umum, agar dapat memantau kesehatannya yaitu "Human Vital Sign Examination Device (Laju Pernafasan dan Tekanan Darah)" yang memiliki tujuan agar masyarakat lebih memperhatikan kesehatannya. Oleh karena itu, pentingnya alat ini ditujukan kepada masyarakat, sehingga pengguna alat ini bisa melakukan pemantauan kondisi fisiologisnya kapanpun. Tetapi tetap dianjurkan untuk melakukan medical check-up kepada ahli medis. Peran alat ini hanya membantu pengguna dalam menentukan pola hidup yang sehat.

Penelitian sebelumnya telah dikembangkan oleh peneliti [3]. Dari hasil pengukuran tersebut, alat tersebut mengambil data dari 10 orang dengan 30 kali pengukuran dan dibandingkan dengan alat pembanding, dan hasil error yang didapat masih memenuhi standar walaupun cenderung tinggi yaitu sebesar $5,5 \%$, tetapi masih masuk dalam toleransi yang diperbolehkan oleh Peraturan Kementerian Kesehatan. Kekurangan pada alat ini yaitu masih tingginya nilai error yang dihasilkan dan data yang didapat kurang presisi. Penelitian sebelumnya telah dikembangkan oleh peneliti [4]. Kemudian penelitian telah dikembangkan oleh peneliti [5]. Berdasarkan penelitian yang telah dilakukan dapat diambil kesimpulan bahwa alat ukur yang telah dirancang dapat bekerja dengan baik pada orang dewasa.

Dari beberapa penelitian tersebut, alat ukur tekanan darah masih menggunakan sensor tekanan MPX5100GP, akan tetapi pada penelitian ini menggunakan sensor tekanan MPX5050GP dan diletakkan pada lengan pasien. Keuntungan menggunakan sensor tekanan MPX5050GP yaitu lebih sensitif dan nilai error dari sensor yang kecil dibawah $0,5 \%$ sehingga menghasilkan data yang lebih presisi. Alat ukur laju pernafasan yang digunakan dari beberapa penelitian diatas masih menggunakan module miccondenser, akan tetapi pada penelitian ini menggunakan sensor FC-04 diletakkan pada masker oksigen, kelebihan dari sensor ini yaitu kepekaan dari sensor bisa diatur melalui potensionya. Kemudian dari beberapa penelitian diatas belum menggunakan teknologi 


\author{
Putra, Harjono \\ Human Vital Sign Examination Device
}

mikrokontroller Arduino dan memiliki jumlah parameter yang terbilang sedikit, maka pada penelitian ini penulis menggunakan teknologi Arduino dan menambahkan beberapa parameter.

\title{
2. METODE PENELITIAN
}

Pada analisis pengujian terdapat parameter yang akan diujikan yaitu nilai tekanan darah dan laju pernafasan yang akan dibandingkan dengan prototype alat yang diusulkan, tensimeter digital OMRON HEM-7203, FLUKE DPM4-1H dan patient monitor UMEC 10. Pengujian ini bertujuan untuk memastikan kesesuaian nilai tekanan darah dan laju pernafasan dari prototype alat yang telah dirancang. Dimana setiap responden akan dilihat hasilnya pada prototype alat penelitian yang telah dirancang dan alat pembanding yang telah disebutkan sebelumnya kemudian akan ditampikan di LCD (Liquid Crystal Display) karakter 4x16. Pengujian dilakukan dengan cara pengambilan data tekanan darah dan laju pernafasan terhadap 5 responden, dengan tiap responden dilakukan pengujian sebanyak 5 kali pengujian.

\subsection{Perancangan Hardware}

Perancangan hardware pada modul yang diusulkan menggunakan beberapa modul rangkaian dan software pemrograman.

\subsubsection{Rangkaian Minimum Sistem}

Rangkaian minimum sistem Gambar 1 berfungsi sebagai kontrol rangkaian. Rangkaian ini merupakan pengendali segala kerja dari alat. Gambar 1 merupakan rangkaian minimum sistem ATMega 328 yang telah dilengkapi dengan ADC (analog to digital converter).

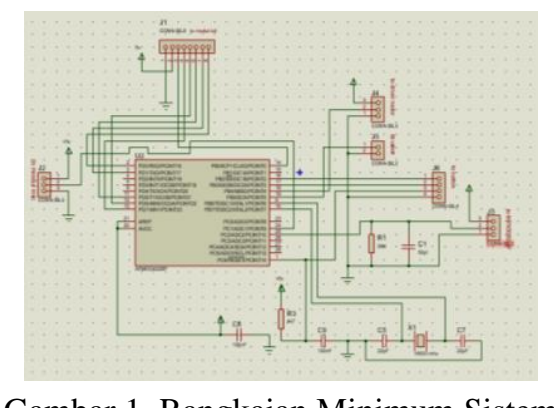

Gambar 1. Rangkaian Minimum Sistem

\subsubsection{Rangkaian LCD $4 \times 16$}

Pada Gambar 2 merupakan rangkaian LCD karakter 4 x 16 dimana LCD sebagai display yang menampilkan setting dari alat yang telah dijalankan oleh program. Untuk menyalakan LCD membutuhkan tegangan $+5 \mathrm{~V}$, pada pin VDD mendapatkan $+5 \mathrm{~V}$, pin VSS mendapatkan ground, pin D4, D5, D6, dan D7 mendapatkan PORT yang ditentukan pada rangkaian minimum sistem.

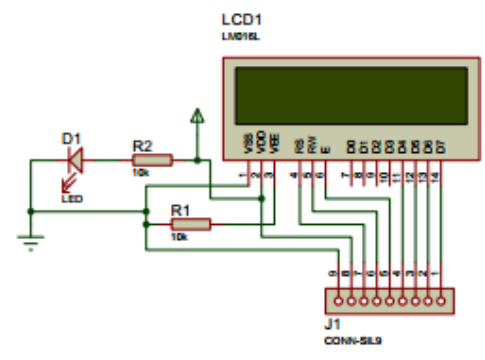

Gambar 2. Rangkaian LCD

\subsubsection{Rangkaian Driver Relay}

Pada Gambar 3 merupakan rangkaian driver relay yang berfungsi sebagai pengendali motor pump. Rangkaian driver relay dihubungkan ke PORTB.4 yang ada pada rangkaian minimum sistem. Jika kaki basis pada transistor BD139 mendapatkan tegangan, maka kaki emitor terhubung 


\section{Putra, Harjono}

Human Vital Sign Examination Device

ke kaki kolektor sehingga kaki ground terhubung ke relay $5 \mathrm{~V}$ dan tegangan pada kaki COM relay terhubung ke motor pump.

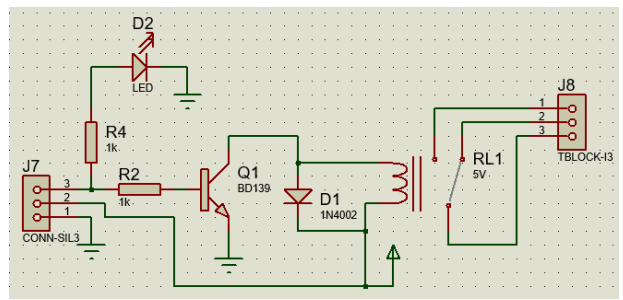

Gambar 3. Rangkaian Driver Relay (5 VDC)

\subsubsection{Rangkaian Sensor MPX5050GP}

Pada Gambar 4 merupakan rangkaian sensor MPX5050GP yang berfungsi sebagai pengukur tekanan.

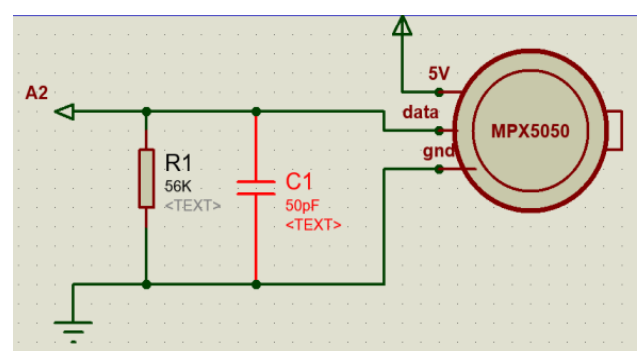

Gambar 4. Rangkaian Sensor MPX5050GP

\subsubsection{Rangkaian Modul Miccondenser}

Pada Gambar 5 merupakan rangkaian modul sensor miccodenser yang berfungsi menerima hembusan nafas dan diterima oleh microphone. Sinyal dari microphone tersebut diteruskan ke rangkaian penguat kemudian diterima oleh rangkaian minimum sistem.

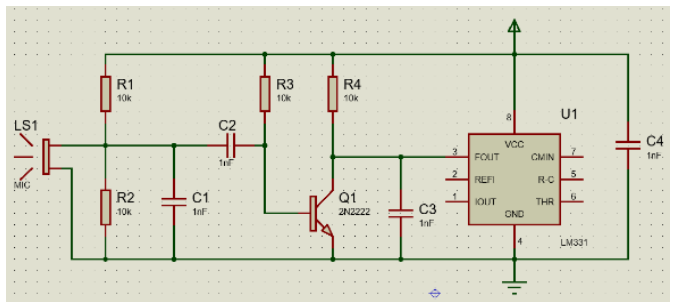

Gambar 5. Rangkaian Sensor Miccodenser

\subsection{Perancangan Software}

Perangkat lunak digunakan untuk memproses sinyal yang didapat dari sensor menggunakan mikrokontroler Arduino Uno sebagai pengolah data. 


\section{Putra, Harjono}

Human Vital Sign Examination Device

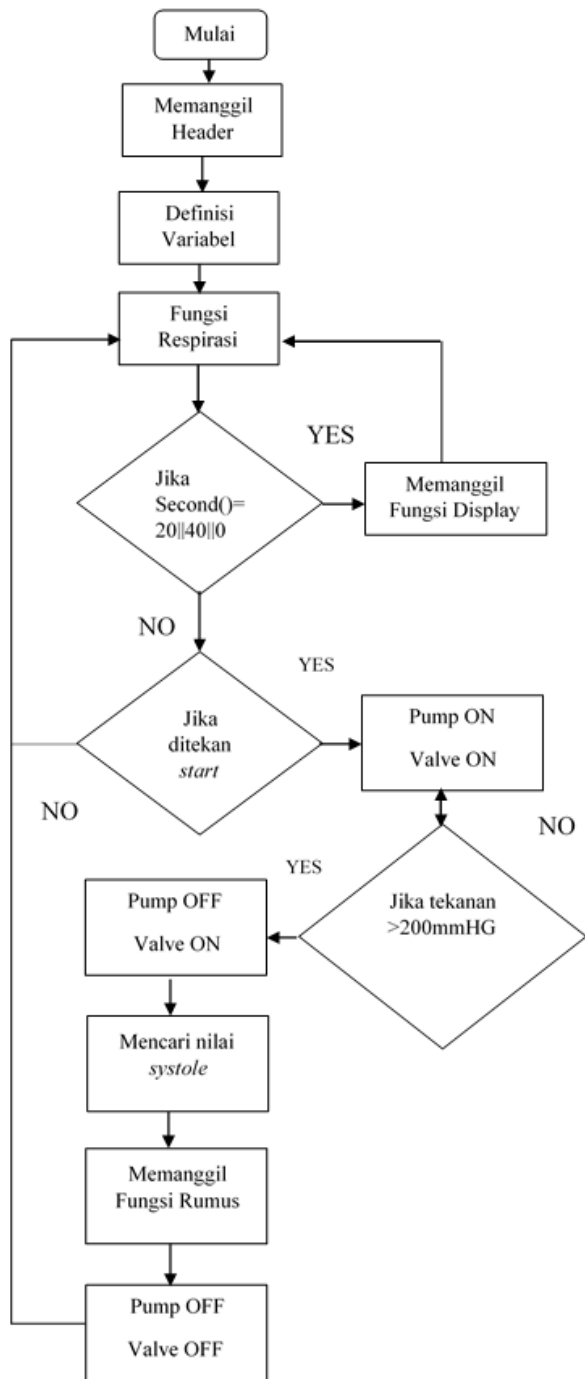

Gambar 6. Diagram Alir Program

\section{HASIL DAN PEMBAHASAN}

\subsection{Hasil Pengujian Dan Analisis Data Tekanan}

Pada

Tabel 1 yang merupakan hasil pengukuran data tekanan darah dengan menggunakan responden sebanyak 5 orang, setiap responden dilakukan pengambilan data sebanyak 5 kali. Pembanding alat ukur yang digunakan yaitu tensimeter digital OMRON HEM-7203. Untuk pengujian membandingkan hasil yang didapat dari prototype alat penelitian dengan alat tensimeter digital OMRON HEM-7203.

Tabel 1. Data Pada Tekanan Darah Sistole Dan Diastole

\begin{tabular}{|c|c|c|c|c|c|c|c|c|}
\hline \multicolumn{8}{|c|}{ Rata-rata Pengukuran Tekanan Darah (mmHg) } \\
\hline \multirow{2}{*}{ Nama } & \multicolumn{2}{|c|}{ Modul TA } & \multicolumn{2}{|c|}{$\begin{array}{c}\text { OMRON } \\
\text { HEM-7203 }\end{array}$} & \multicolumn{2}{c|}{$\begin{array}{c}\text { Absolut Error } \\
\text { (mmHg) }\end{array}$} & \multicolumn{2}{c|}{ Persentase Error (\%) } \\
\cline { 2 - 10 } & Sys & Dys & Sys & Dys & Sys & Dys & Sys & Dys \\
\hline \multirow{2}{*}{ Putra } & 110.8 & 62 & 114.6 & 64 & 6.2 & 4.4 & 5.36 & 6.84 \\
\hline Viryawan & 142 & 93.8 & 141.2 & 90.2 & 8.8 & 3.6 & 6.16 & 3.99 \\
\hline
\end{tabular}

Medika Teknika : Jurnal Teknik Elektromedik Indonesia, Vol 02 No. 1, Oktober 2020| 17 
Putra, Harjono

Human Vital Sign Examination Device

\begin{tabular}{|c|c|c|c|c|c|c|c|c|}
\hline Erina & 120.2 & 83.6 & 116.8 & 85.8 & 4.2 & 7.8 & 3.64 & 8.88 \\
\hline Alfana & 110 & 64.2 & 114.2 & 63 & 4.2 & 2.4 & 3.64 & 3.83 \\
\hline Rustami & 118.2 & 73.2 & 114.8 & 70.6 & 5 & 4.6 & 4.42 & 6.50 \\
\hline
\end{tabular}

Dari hasil perhitungan rata-rata tekanan sistole dan diastole pada Tabel 1 Maka didapatkan data rata-rata kesalahan absolut dan persentase error. Kesalahan absolut 6,2 $\mathrm{mmHg}$ pada tekanan sistole dengan persentase error $5,36 \%$ dan $4,4 \mathrm{mmHg}$ pada tekanan diastole dengan persentase error $6,84 \%$ pada responden 1, kesalahan absolut $8,8 \mathrm{mmHg}$ pada tekanan sistole dengan persentase error $6,16 \%$ dan 3,6 $\mathrm{mmHg}$ pada tekanan diastole dengan persentase error 3,99\% pada responden 2, kesalahan absolut $4,2 \mathrm{mmHg}$ pada tekanan sistole dengan persentase error $3,64 \%$ dan $7,8 \mathrm{mmHg}$ dengan persentase error $8,8 \%$ pada tekanan diastole pada responden 3 , kesalahan absolut 4,2 $\mathrm{mmHg}$ dengan persentase error $3,64 \%$ pada tekanan sistole dan $2,4 \mathrm{mmHg}$ dengan persentase error $3,83 \%$ pada tekanan diastole pada responden 4 , kesalahan absolut $5 \mathrm{mmHg}$ dengan persentase error $4,42 \%$ pada tekanan sistole dan $4,6 \mathrm{mmHg}$ dengan persentase error $6,5 \%$ pada tekanan diastole pada responden 5 .

\subsection{Hasil Pengujian Tekanan dengan FLUKE DPM4-1H (mmHg)}

Pada Tabel 2 yang merupakan hasil pengukuran data tekanan dengan pengambilan data sebanyak 5 kali dalam 1 percobaan. Pembanding alat ukur menggunakan FLUKE DPM4-1H. Untuk pengujian membandingkan hasil yang didapat dari prototype alat tugas akhir dengan alat FLUKE DPM4-1H.

Tabel 2. Data Tekanan Menggunakan DPM4-1H

\begin{tabular}{|c|c|c|c|c|}
\hline \multicolumn{5}{|c|}{ Rata-rata Pengukuran Tekanan Darah (mmHg) } \\
\hline Percobaan & $\begin{array}{c}\text { Module TA } \\
(\mathrm{mmHg})\end{array}$ & $\begin{array}{c}\text { FLUKE DPM4-1H } \\
(\mathrm{mmHg})\end{array}$ & $\begin{array}{c}\text { Absolut Error } \\
(\mathrm{mmHg})\end{array}$ & Persentase Error (\%) \\
\hline 1 & 132.2 & 134.78 & 4.98 & 4.8 \\
\hline 2 & 151.4 & 145.74 & 8.46 & 8.8 \\
\hline 3 & 135.2 & 133.22 & 4.78 & 4.8 \\
\hline 4 & 121.2 & 125.96 & 4.76 & 8.8 \\
\hline 5 & 131.6 & 129.66 & 10.06 & \\
\hline
\end{tabular}

Dari hasil perhitungan rata-rata tekanan sistole dan tekanan diastole pada Tabel 2 maka didapatkan rata-rata kesalahan absolut dan persentase error. Kesalahan absolut 4,98 $\mathrm{mmHg}$ dengan persentase error $4,8 \%$ pada percobaan pertama, kesalahan absolut $8,46 \mathrm{mmHg}$ dengan persentase error $8,8 \%$ pada percobaan kedua, kesalahan absolut $4,78 \mathrm{mmHg}$ dengan persentase error $4 \%$ pada percobaan ketiga.

\section{KESIMPULAN}

Setelah melakukan proses perancangan dan studi literatur perencanaan, pengujian alat dan pengambilan data, maka dapat disimpulkan sebagai berikut.

Tingkat error yang dihasilkan setelah melakukan pengukuran dan perhitungan untuk error tekanan darah terendah yaitu $-0,8 \mathrm{mmHg}$ dengan persentase $0,57 \%$ pada tekanan sistole dan error $1,2 \mathrm{mmHg}$ dengan persentase $1,9 \%$ pada tekanan diastole, dan error tekanan darah yang paling besar yaitu 4,2 $\mathrm{mmHg}$ dengan persentase $3,68 \%$ pada tekanan sistole dan $-3,6 \mathrm{mmHg}$ dengan persentase $3,99 \%$ pada tekanan diastole, sedangkan pada laju pernafasan nilai error tertinggi yaitu 0,8 brpm dengan persentase 5\% dan nilai terendah yaitu 0,2 brpm dengan persentase $1,08 \%$.

Persentase error yang dihasilkan setelah melakukan pengujian tekanan dengan FLUKE DPM-4. Nilai error terendah yaitu $1 \%$ dengan selisih error dalam mmHg sebesar $-1,94 \mathrm{mmHg}$, dan nilai error tertinggi yaitu $4 \%$ dengan selisih error dalam mmHg sebesar $-5,66 \mathrm{mmHg}$.

\section{DAFTAR PUSTAKA}

[1] "Masalah Kesehatan: Hipertensi Dan Masalahnya «Solusi Kesehatan Anda.".

Medika Teknika : Jurnal Teknik Elektromedik Indonesia, Vol 02 No. 1, Oktober 2020|18 


\section{Putra, Harjono}

Human Vital Sign Examination Device

[2] "Tanda-Tanda Vital Sesuai Tingkat Usia.".

[3] O. Handayani, "Alat Pengukur Tekanan Darah Berbasis Atmega8 Dilengkapi Dengan Indikator Tekanan Darah,” Aug. 2017.

[4] K. Gusfazli, "Alat Ukur Heart And Respiration Rate Berbasi Atmega 16," Aug. 2017.

[5] G. M. S. Fi, "Gusti M Syabilal Fikar Program Studi S1 Teknobiomedik,” 2016. 